2011-01-01

\title{
In-Silico Hyperthermia Performance of a Near-Field Patch Antenna at Various Positions on a Human Body Model
}

\author{
Sergio Curto \\ Technological University Dublin, sergiocurtoramos@gmail.com \\ Terrence See \\ Institute for Infocomm Research \\ Patrick McEvoy \\ Technological University Dublin, patrick.mcevoy@tudublin.ie
}

See next page for additional authors

Follow this and additional works at: https://arrow.tudublin.ie/ahfrcart

Part of the Biomedical Devices and Instrumentation Commons, and the Systems and Communications Commons

\section{Recommended Citation}

Curto, S. et al. (2011) In-Silico Hyperthermia Performance of a Near-Field Patch Antenna at Various Positions on a Human Body Model. IET Microwaves, Antennas \& Propagation. Volume 5, no. 12, p.1408-1415. 2011. doi:10.1049/iet-map.2010.0611

This Article is brought to you for free and open access by the Antenna \& High Frequency Research Centre at ARROW@TU Dublin. It has been accepted for inclusion in Articles by an authorized administrator of ARROW@TU

Dublin. For more information, please contact

arrow.admin@tudublin.ie, aisling.coyne@tudublin.ie, gerard.connolly@tudublin.ie.

Funder: IRCSET

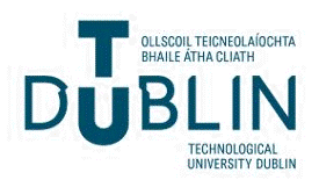


Authors

Sergio Curto, Terrence See, Patrick McEvoy, Max Ammann, and Zhi Ning Chen

This article is available at ARROW@TU Dublin: https://arrow.tudublin.ie/ahfrcart/22 
This paper is a preprint of a paper accepted by IET Microwaves, Antennas \& Propagation and is subject to Institution of Engineering and Technology Copyright. When the final version is published, the copy of record will be available at IET Digital Library.

\title{
In-silico Hyperthermia Performance of a Near-Field Patch Antenna at Various Positions on a Human Body Model
}

\author{
S. Curto ${ }^{1}$, T. S. P. See ${ }^{2}$, P. McEvoy ${ }^{1}$, M. J. Ammann ${ }^{1}$ and Z. N. Chen ${ }^{2}$
}

${ }^{1}$ Antenna and High Frequency Research Centre, Dublin Institute of Technology, Dublin 8, Ireland

${ }^{2}$ RF \& Optical Department, Institute for Infocomm Research, 1 Fusionopolis Way, \#21-01 Connexis, South Tower, Singapore 138632

E-mail: ammann@ieee.org

Abstract: A compact patch applicator designed to enhance targeted energy coupling at $434 \mathrm{MHz}$ is a key enabler for sensitising temperature increments in body regions containing superficial tumours. A detailed FDTD body model is used to explore simulated RF coupling and temperature increments for typical clinical conditions. The antenna impedance matching, specific absorption rate and thermal distribution parameters are evaluated to identify applied performance outcomes. The analysis reveals physiological-RF coupling patterns for an optimised closely-coupled single element applicator.

\section{Introduction}

The effectiveness of radio-frequency (RF) hyperthermia treatment systems for oncology [1] or injured muscular tissue [2] is proportional to the transfer of electromagnetic energy into the targeted body region. Antenna applicators with RF sources of sufficient power are selected for an energy deployment rate to overcome cooling that vascular perfusion and perspiration contribute to natural thermal regulation. Single element near-field antenna applicators are suited to lower-cost clinical systems for tissue treatment at superficial depths [3]. Applied clinical setup models require enhanced biological details over conventional homogeneous or planar layered body models. The performance of the near-field-loaded antenna reported here is evaluated with a numerical human model for resonant frequency and impedance match insensitivity to dielectric load variations at different anatomy locations.

Positioning the antenna radiating near-field in close proximity to a patient increases the mutual interaction of the radiator and the body. However, precipitous sub-wavelength variations in near-fields produce irregular amplitude and phase patterns that add 
complexity to the analysis of the antenna coupling performance. Furthermore, the electric field components scatter among the arbitrary shapes and layers of differing tissues in the treatment area. The energy coupling is dependent on multiple factors, inter alia, the radiation pattern, variation of proximity from the tissue, varying waterbolus profile depths that conform to the body surface, diversity of anatomical shapes, electromagnetic responses in biological tissues and furthermore by individual physiological responses due to age, metabolic rates or a pathological stage.

A near-field hyperthermia antenna design should be capable of targeting energy without causing adverse power concentrations in the superficial tissue layers. Measurement of distributed thermal patterns in bulk tissue is difficult and design analysis is more expedient in silico provided the software model is a reasonably accurate representation of in vitro clinical conditions. One-dimensional [4], coarse-resolution homogeneous [5] and planar-layered [6] numerical human models can reveal a basic distribution of coupled energy. However, simplified models can compromise the clinical treatment setup and patient comfort by underestimating the actual peak specific absorption rate (SAR) and localised high intensity patterns.

In order to assess a range of coupling variations for different body areas, the antenna was modelled at the rear of the head, between the shoulder blades (inter-scapular) and in front of the stomach (epigastrium). Surface-cooling waterboluses [7, 8] which conformed to the body shapes were included for improved representation of clinical treatment setups. Models reveal the energy distributions and their dependence on the geometric features of the applicator antenna. Furthermore, indicative body thermal responses to the applicator help to establish useful basis for pre-treatment planning [9]. The antenna design seeks to offer a stable coupling pattern for a range of anatomy features [10]. This permits technicians to apply treatment to various locations of a patient without having select alternate pre-optimised applicators.

\section{Materials and Methodology}

\subsection{Hyperthermia Antenna Design}

Fig. 1 shows the compact $434 \mathrm{MHz}$ printed patch antenna on a low loss tangent, double-sided Taconic RF-35 dielectric substrate, $\varepsilon_{\mathrm{r}}=3.5$, tan $\delta=0.0018$. The slotted features are designed to minimize substrate dimensions to $130 \mathrm{~mm} \times 130 \mathrm{~mm} \times 3 \mathrm{~mm}$ and to focus the radiated energy concentrically into the targeted tissue treatment zone. A description of the antenna design process and a comparison of the basic functionality with other applicator approaches are reported in [11]. 


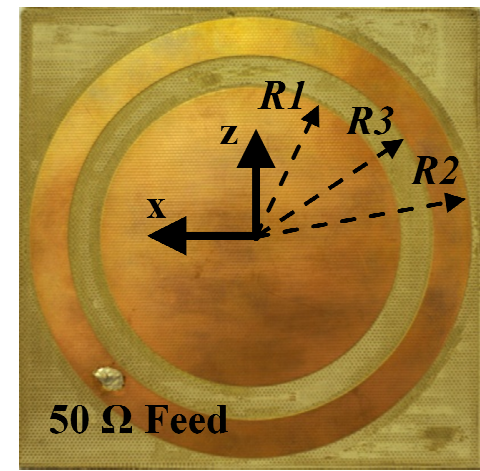

(a)

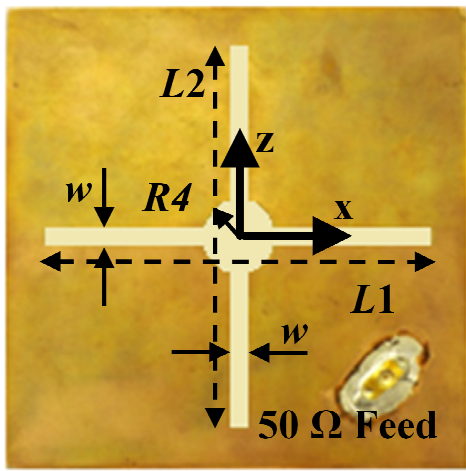

(b)

Figure 1 Fabricated antenna and dimensions at the (a) front side (towards tissue) and (b) rear side (away from tissue). The dimensions are: $R 1=42 \mathrm{~mm}, R 2=51 \mathrm{~mm}, R 3=62 \mathrm{~mm}, R 4=10 \mathrm{~mm}, L 1=106 \mathrm{~mm}, L 2=108 \mathrm{~mm}, w=4 \mathrm{~mm}$. The $50 \Omega$ feed is in the concentric annular ring at coordinates $(x, z)=(40,-40) \mathrm{mm}$.

\subsection{Human Body Model}

Extensive computational resources are necessary for the full-wave electromagnetic simulation of detailed anatomy models. Free-space wavelengths of $0.7 \mathrm{~m}$ far exceed the dimensions of the morphological features which range from $1 \times 10^{-9} \mathrm{~m}$ for molecules, $1 \times 10^{-7} \mathrm{~m}$ for cells and millimetre scales for tissues, etc. Intricate elements like nerve fibres, blood vessels or muscle fibres are inherently anisotropic but such detail is discarded by classifying their enclosing tissues as homogeneous Debye materials. However, multi-tissue whole-body models provide an improved analysis baseline for complex electromagnetic coupling with arbitrary-shaped tissues $[12,13]$ and avoid simulation artefacts due to truncation of large organs and conductive tissues. The SAR and temperature profile estimates can enhance both the antenna design and clinical dosage planning [14].

The Remcom human body derived from the Visible Human Project data [15] was selected as the main heterogeneous model with the XFDTD electromagnetic solver [16]. The human model has a height of $1.8 \mathrm{~m}$, a mass of $103 \mathrm{~kg}$ and comprises twenty-three tissue types with frequency-dependent electrical and thermal properties. The body model had a predefined $5 \mathrm{~mm}$ voxel resolution which was segmented from an adult male tomography of magnetic resonance images with $1 \mathrm{~mm}$ step cross-sections [15]. It was centre located in a grid with dimensions $0.77 \times 0.52 \times 2.08 \mathrm{~m}$ with perfectly matched absorbing layers of seven cells deep with a minimum separation distance of $100 \mathrm{~mm}$. The conductivity, density and relative permittivity values for the simulated body tissues are listed in Table I [17] and thermal properties are listed in Table II [16], (in the appendix).

An adaptive mesh with a minimum cubic cell dimension of $1 \mathrm{~mm}\left(\sim 1.4 \times 10^{-3} \times \lambda_{0}\right)$ was defined for the antenna structure and the targeted body areas. The mesh resolutions were a trade between available computational resources and inaccuracies due to electric field or surface current orientation alignments with under-resolved geometric features. The simulation boundary conditions were perfectly matched absorbing layer of seven cells deep. More than 20 million cells were generated, which required 1.03 Gbytes of memory and typically 10 hours on a $3.4 \mathrm{GHz}$ PC with 4 Gbytes of RAM. 


\subsection{Antenna Body Positions}

The conductivity-to-density ratio column in Table I indicates absorption rates of the tissue types. While fat absorbs only $6 \%$ that of muscle, the antenna-body coupling is also influenced by proximity, aperture loading of tissue volumes, contoured tissue layering and organ shapes. A range of coupling performance was assessed at three locations shown in Fig. 2. The antenna was oriented perpendicular to the sagittal plane and parallel with and centred on the coronal plane.

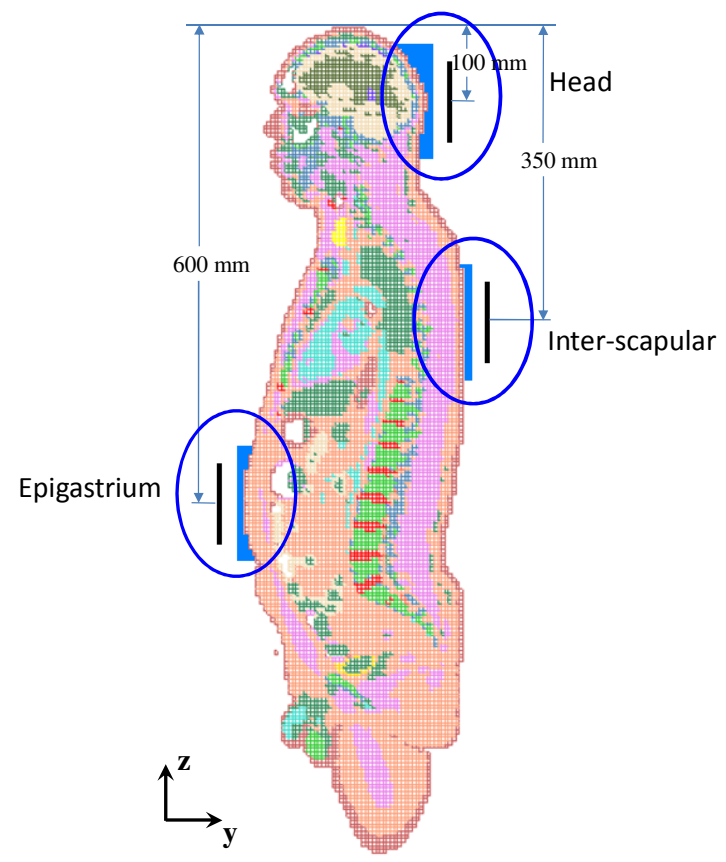

Figure 2 Sagittal plane section of human body model and antenna positions

The tissue compositions and shapes differ at each position, as detailed in Fig. 3. The head area model comprised a $5 \mathrm{~mm}$ layer of skin over a layer of yellow marrow which contains cortical and cancellous bone structures with cerebrospinal fluid involving grey and white matter. The model of the inter-scapular area of the back consisted of $10 \mathrm{~mm}$-thick skin layer next to a variable layer of fat tissue and muscle. The cortical bone and white matter cover the spine, which was modelled as cancellous bone, cartilage and nerves. 


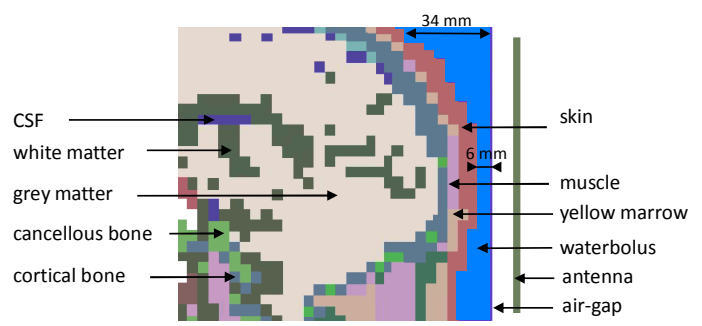

(a)

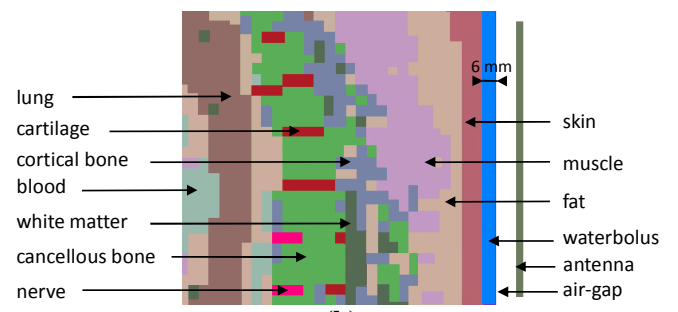

(b)

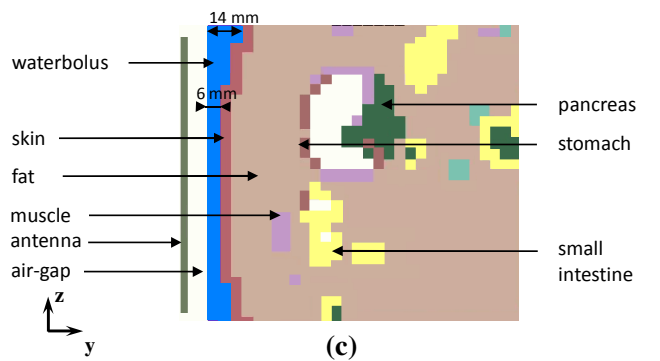

Figure 3 Tissue structures in the (a) head, (b) inter-scapular and (c) epigastrium areas.

The epigastrium model had a skin layer with a very thick sub-layer of fat (around $100 \mathrm{~mm}$ ) which contains muscle, small intestine, pancreas and the stomach. While the tissue layer thicknesses and shapes are distorted following the MRI, segmentation and voxel sampling, the multi-tissue features are an improved portrayal compared to homogeneous and planar layer models.

When the antenna is positioned at the head, it can be used to treat various types of brain or meninges cancers. Melanoma, vertebral or sarcoma cancers can be targeted from the inter-scapular position and superficial adenocarcinoma can be treated from the epigastrium.

Clinical applications employ waterboluses to cool the irradiated surface skin area and to improve the coupling. Unlike previous studies of frequency dependent surface wave oscillations with planar body models $[7,8]$ the water-bolus profile depths conformed to body's curved areas. The de-ionised water had permittivity $\varepsilon_{\mathrm{r}}=76$, conductivity $\sigma=0.001 \mathrm{Sm}^{-1}$ and covered a $200 \times 200 \mathrm{~mm}$ area. The waterbolus thickness from the antenna centre to the edge ranged from $6 \mathrm{~mm}$ to $34 \mathrm{~mm}$. The antenna was positioned close to the skin to minimize power loss in the bolus [10] but with a gap to minimize sensitivity to variations between patients. Approximately $22.4 \%, 100 \%$ and $41.4 \%$ of the antenna radiating surface was loaded by the close proximity of the body features at the respective head, inter-scapular and epigastrium positions. 


\subsection{SAR and Temperature Analysis}

SAR patterns were normalised to the antenna input power of $1 \mathrm{~W}$ and evaluated for $1 \mathrm{~g}$ averaged spatial peak SAR to mitigate against multi-tissue averaging across tissue boundaries $[18,19]$. Iso-line plots for $50 \%, 25 \%$ and $1 / \mathrm{e}^{2} \mathrm{SAR}$ penetration depths were selected for consistency with methods employed in [20, 21] and European Society for Hyperthermic Oncology guidelines for homogeneous or layered body models.

While temperature increments to $45^{\circ} \mathrm{C}$ and above are reported as hyperthermia treatment objectives, the doses can be referenced to cumulative equivalent minutes for a $43{ }^{\circ} \mathrm{C}$ threshold [22]. The aim is to enhance the effectiveness of the radiotherapy with a $\mathrm{RF}$ power level setting that avoids thermal tolerance during follow up clinical treatment sessions [23]. The Pennes bio-heat equation [24] was used to calculate the temperature increments in a $23^{\circ} \mathrm{C}$ background within the Remcom application.

\subsection{Methodology}

The waterbolus thickness and the waterbolous-antenna air-gap dimensions were optimised for $\left|S_{11}\right|$ and peak SAR using the heterogeneous body model at the three sample treatment positions.

A comparison of body models was made to quantify the effects that body shapes and tissue layers have on the predicted coupling with the antenna. The comparison models were a planar layered model (comprising skin, fat and muscle) and a homogeneous body model (same body shape than the heterogeneous model, but with all the tissues with properties of muscle tissue).

The temperature distribution analysis uses the heterogeneous body model but the calculation does not account for natural physiological responses to temperature rises and probably underestimates the dynamics of the natural cooling processes [14]. Accordingly, the static perfusion rates of the tissues were doubled from the base values to quantify additional antenna input powers at the three body treatment positions.

Additionally, the simulation technique was corroborated by measurements of the DASY4 SAR setup with a homogenous lossy liquid phantom.

\section{$3 \quad$ Results}

\subsection{Waterbolus Effects}

Waterboluses with thicknesses 6,8 , and $10 \mathrm{~mm}$ along the centre of the antenna radiating axis were evaluated for optimum $\left|S_{11}\right|$ and peak SAR performance with the heterogeneous body model. The various dimensions were assessed with a range of antenna-waterbolus air-gaps between $2-16 \mathrm{~mm}$ in $2 \mathrm{~mm}$ steps. Thinner waterbolus dimensions were discounted for limited cooling capability and waterboluses in the 5-10 mm range produced more even SAR distributions [7, 8]. Fig. 4(a) shows that increasing the waterbolus thickness with a fixed $10 \mathrm{~mm}$ air-gap impaired the impedance matching but did not affect the SAR significantly. 
Fig. 4(b) illustrates that air-gap increment from $2-12 \mathrm{~mm}$ for a 6-mm thick waterbolus improves the impedance matching but extended air-gap dimensions degrade the matching. The peak SAR reduces as the air-gap increases due to the bigger antenna-tissue separation. A 6-mm-thick waterbolus with a 10-mm air-gap produces the highest peak SAR with a corresponding $\left|S_{11}\right|$ of around $-8 \mathrm{~dB}$ at $434 \mathrm{MHz}$. This setup configuration is used in the clinical modelling of the following results.

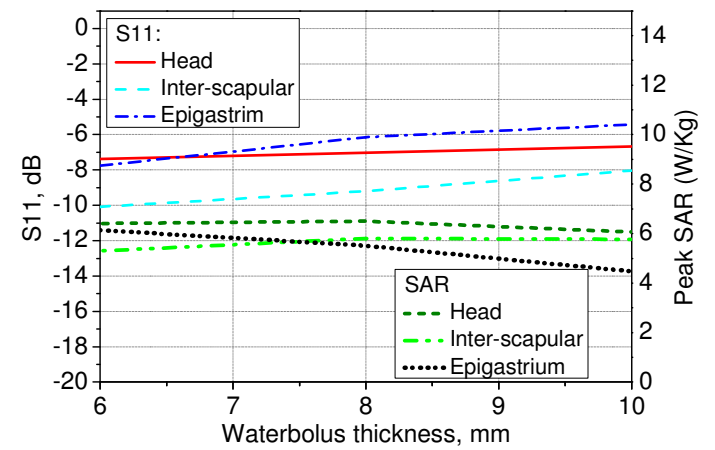

(a)

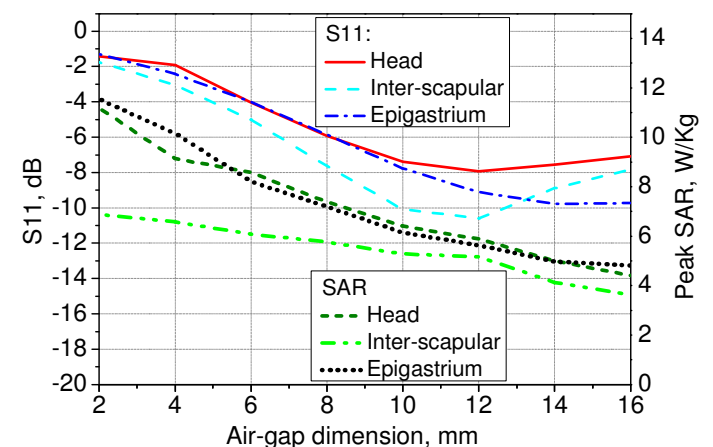

(b)

Figure $4\left|S_{1 I}\right|$ and peak SAR at $434 \mathrm{MHz}$ for the different (a) waterbolus thicknesses with $10 \mathrm{~mm}$ air-gap dimension and (b) air-gap dimensions with $6 \mathrm{~mm}$ waterbolus thickness for the heterogeneous body model

\subsection{In-Silico Specific Absorption Rate}

Initial analysis using a planar tri-layered tissue model and a homogeneous (muscle equivalent) body model explored influences of tissue loading and anatomical shapes on the power deposition mechanism. A $200 \times 200 \mathrm{~mm}$ planar model comprised layers of skin $(5 \mathrm{~mm})$, fat $(20 \mathrm{~mm})$ and muscle $(75 \mathrm{~mm})$ for comparison with the heterogeneous epigastrium features. The results are shown in Table III.

TABLE III PLANAR LAYERED AND HOMOGENEOUS MODELS: PEAK SAR VALUES AND PENETRATION DEPTHS

\begin{tabular}{lcccc}
\hline \hline Model Area & Peak & $50 \%$ & $25 \%$ & $1 / e^{2}$ \\
& SAR & SAR & SAR & SAR \\
& $(\mathrm{W} / \mathrm{Kg})$ & $(\mathrm{mm})$ & $(\mathrm{mm})$ & $(\mathrm{mm})$ \\
\hline
\end{tabular}




$\begin{array}{lcccc}\text { Planar Layered } & 5.54 & 7 & 9 & 51 \\ \text { Head } & 4.20 & 22 & 37 & 53 \\ \text { Inter-scapular } & 3.75 & 32 & 49 & 60 \\ \text { Epigastrium } & 3.95 & 25 & 47 & 56\end{array}$

Figs. 5(a-c) show the SAR patterns in the sagittal plane for the homogeneous muscle model at the head, inter-scapular and epigastrium positions. The peak SAR is aligned with the antenna radiating centre axis and the smooth distributions were only distorted at the epigastrium due to discontinuities at the air-filled cavities in the stomach and small intestine. Table III summarises the SAR and penetration depths for the planar layered and homogeneous muscle body models. Figs. 5(d-f) show the sagittal plane SAR patterns for the heterogeneous model at the head, inter-scapular and epigastrium positions. The peak SAR is $6 \pm 1 \mathrm{~mm}$ below the surface and is aligned with the feed diagonal and the antenna centre. By inspection, the $50 \%$ iso-SAR corresponds with the skin-fat interface and there are less absorbing sub-layers due to yellow marrow at the head and fat tissue at the inter-scapular and epigastrium positions. Secondary higher absorption zones occur below the yellow marrow and fat layers, which correspond with the antenna centre and occur in tissues with higher conductivity-to-density ratio, in particular, gray matter in the head, muscle in the inter-scapular position and the small intestine in the epigastrium. Table IV summarises the SAR and penetration depths for the heterogeneous model. 


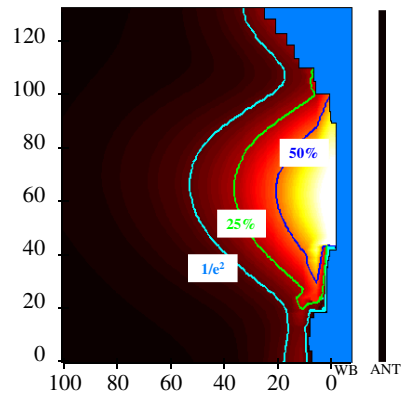

(a)

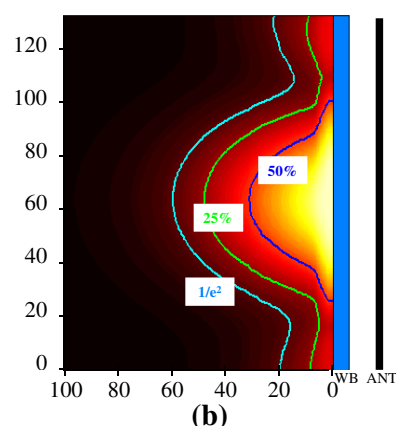

(b)

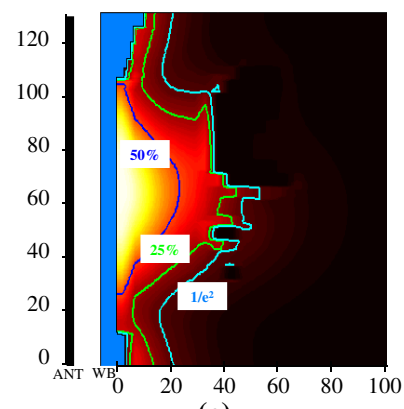

$\stackrel{\mathrm{Z}, \mathrm{mm}}{\longrightarrow} \mathrm{Y,mm}$

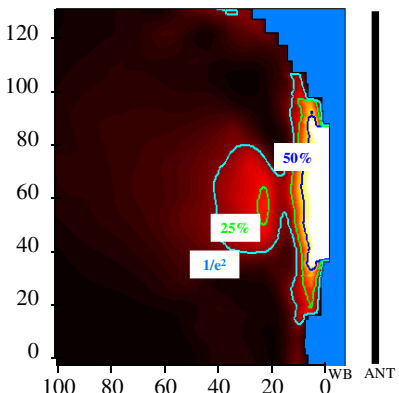

(d)

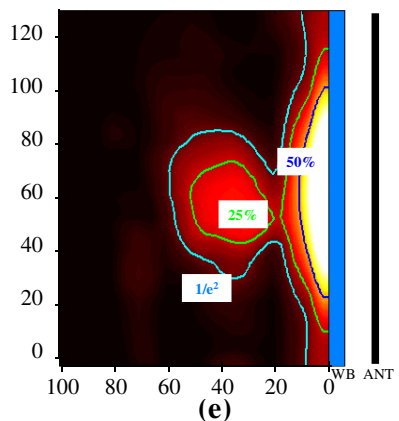

(e)

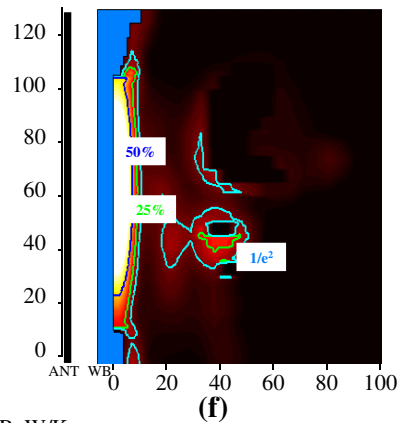

SAR, W/Kg

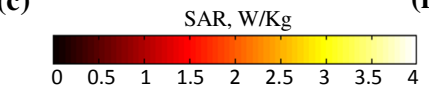

Figure 5 SAR patterns in the sagittal plane for the homogeneous (muscle) and heterogeneous body models at ( $a$ \& $d)$ head, ( $b$ \& $e$ ) inter-scapular and $(c \& f)$ epigastrium positions

TABLE IV Heterogeneous Body Model PEAK SAR VALUES AND PENETRATion DEPTHS

\begin{tabular}{|c|c|c|c|c|c|}
\hline Model Area & Peak SAR (W/Kg) & (50\% SAR & $25 \%$ & $1 / e^{2}$ & Secondary \\
\hline & & $(m m)$ & $S A R(m m)$ & $S A R(m m)$ & $25 \% \mathrm{SAR}(\mathrm{mm})$ \\
\hline Head & 6.41 & 10 & 15 & 44 & 28 \\
\hline Inter-scapular & 5.28 & 10 & 17 & 60 & 52 \\
\hline Epigastrium & 6.14 & 7 & 9 & 55 & 51 \\
\hline
\end{tabular}




\subsection{In-Silico Temperature}

The temperature response to energy deposition at the various body positions along the central sagittal plane of the heterogeneous body model is shown in Fig. 6 . The waterbolus cooled the surface temperature to an approximate $5 \mathrm{~mm}$ depth. The $6{ }^{\circ} \mathrm{C}$ rise to the target temperature of $43{ }^{\circ} \mathrm{C}$ required an input power to the model positions of $75 \mathrm{~W}$ at the head, $92 \mathrm{~W}$ at the inter-scapular and $78 \mathrm{~W}$ at the epigastrium. While the SAR peaks dominated near the surface, the energy penetration profile and the tissue electrical and thermal properties combine to influence the resultant thermal changes. The strong perfusion rate in the head has limited the peak temperature to only just reaching $43{ }^{\circ} \mathrm{C}$. The maximum temperature rise in the inter-scapular position occurs at a shallower depth as compared to the peak SAR penetration. A secondary peak in the temperature rise corresponds with the $1 / \mathrm{e}^{2}$ iso-SAR contour. The peak temperature increments in the epigastrium occur mainly in the small intestine and stomach cavities.

The doubled perfusion rates required additional input powers of $4 \mathrm{~W}(79 \mathrm{~W})$ at the head, $7 \mathrm{~W}(99 \mathrm{~W})$ at the inter-scapular location and $3 \mathrm{~W}(81 \mathrm{~W})$ at the epigastrium to reach the target temperature of $43{ }^{\circ} \mathrm{C}$.

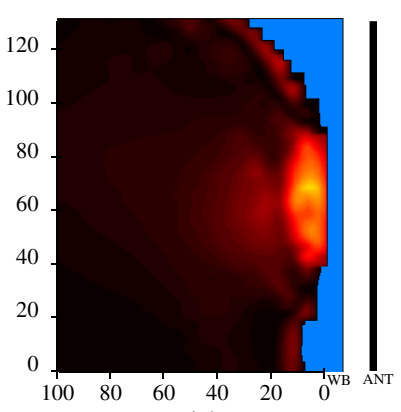

(a)

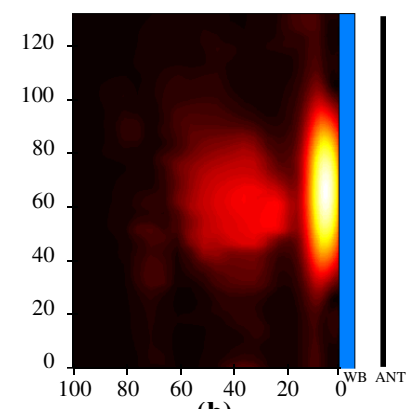

(b)

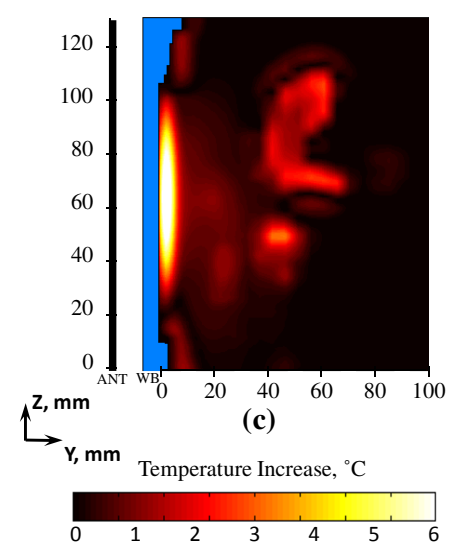


Figure 6 Sagittal plane temperature distributions for (a) head, (b) inter-scapular and (c) epigastrium positions with applied powers of 75, 92 and $78 \mathrm{~W}$ respectively, for the heterogeneous body model.

\subsection{Model Validation}

A comparison SAR measurement of a tissue-equivalent lossy liquid, using a SPEAG Dosimetric Assessment System [25], was used to corroborate the simulation approach. The robotic controlled precision probe was scanned in the $X$-, $Z$-axes with $1 \mathrm{~mm}$ step resolution and at a $4 \mathrm{~mm}$ distance from the inner surface of the 2-mm thick fibreglass phantom shell $\left(\varepsilon_{r}=3.7\right)$. The parameters of the water-sugar based homogeneous liquid phantom were measured as dielectric constant $\varepsilon_{r}=45.07$, conductivity $\sigma=0.82 \mathrm{~S} / \mathrm{m}$ and density $\rho=1250 \mathrm{~kg} / \mathrm{m}^{3}$ at $434 \mathrm{MHz}$. Following a system calibration on a standardised dipole [26], the test antenna with $1 \mathrm{~W}$ input power was centred $10 \mathrm{~mm}$ distant from the flat section of the phantom without a waterbolus, as shown in Fig. 7.

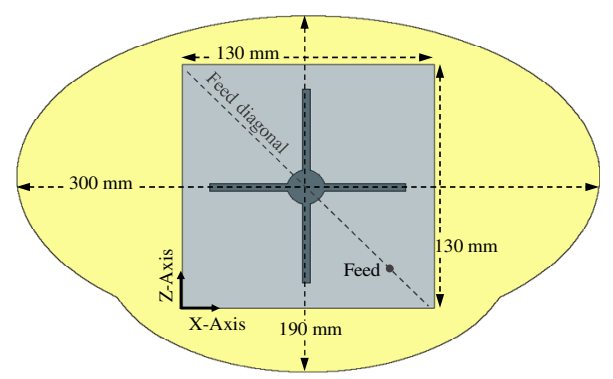

Figure 7 Antenna position at the base of the DASY phantom

The simulated and measured SAR patterns are shown in Fig. 8. The peak SAR occurs along the feed diagonal axis with a quasi-symmetric pattern on either side. The simulated and measured peak SAR values are $1.76 \mathrm{~W} / \mathrm{kg}$ and $1.68 \mathrm{~W} / \mathrm{kg}$, respectively. Similarly, the simulated and measured iso-50\% SAR enclosed areas of $67.25 \mathrm{~cm}^{2}$ and $65.25 \mathrm{~cm}^{2}$, respectively and the iso- $25 \%$ SAR enclosed areas of $146 \mathrm{~cm}^{2}$ and $139 \mathrm{~cm}^{2}$, respectively. Correspondingly, the discrepancies between simulated and measured peak SAR, iso-50\% SAR enclosed area, and iso- $25 \%$ SAR enclosed area are $4.54 \%, 2.97 \%$ and $4.79 \%$. The small variances are partially attributed to measurement sensitivities to the antenna-phantom alignment (typically $6 \%$ for $0.5 \mathrm{~mm}$ position inaccuracy) and phantom dielectric parameter tolerances (typically 5 - 10\%) [25]. Fig. 9 shows the $\left|S_{11}\right|$ that accounts for proximity loading by the liquid phantom dielectric. The $-8 \mathrm{~dB}$ simulated bandwidth of $18.8 \mathrm{MHz}(432.3-451.0 \mathrm{MHz})$ compares reasonably to a 29.9 MHz (424.4-454.3 MHz) measured bandwidth. 


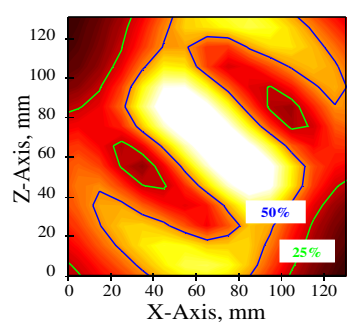

(a)

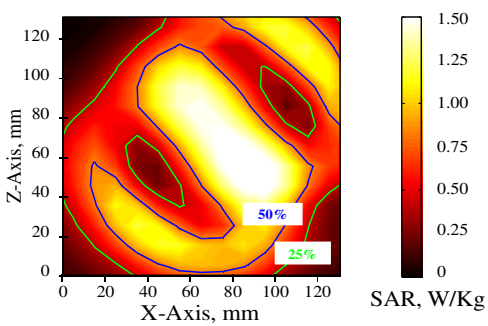

(b)

Figure 8 SAR distribution (a) simulated and (b) measured

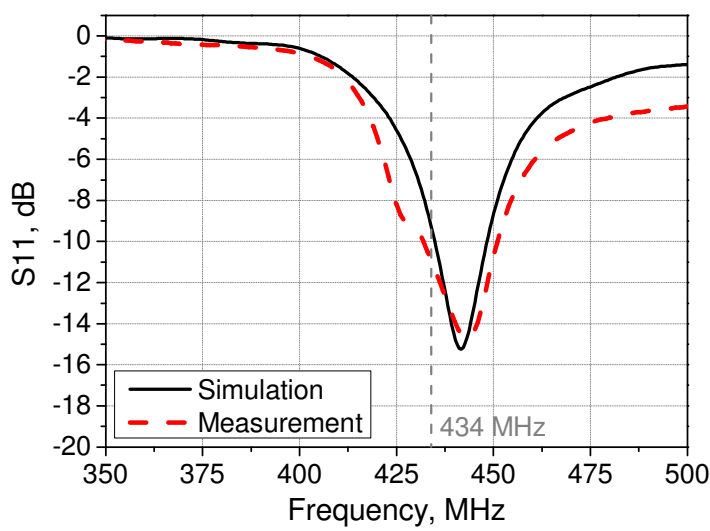

Figure $9\left|S_{11}\right|$ of the antenna at $10 \mathrm{~mm}$ from DASY phantom

\section{Discussion}

While comparisons of cubic cell sizes in human body models have indicated that a finer resolution is only necessary for SAR accuracy in tiny organs (e.g. eye lens) [13], the advanced detail in the body model used here reveals some of the additional complexities in the coupling to multiple tissues. A planar tissue model with equivalent tissue layer thicknesses for the epigastrium underestimated the peak SAR by $9.77 \%$ compared to the heterogeneous body model.

Comparison of a rectangular waterbolus next to a planar homogeneous muscle and fat-muscle layered models showed that waterbolus thickness is a critical parameter for clinical hyperthermia applications [7, 8]. The optimum thickness of the waterbolus in terms of impedance matching and peak SAR for the three antenna locations has been found to be $6 \mathrm{~mm}$ at the antenna radiating axis, but the various body shapes produces different waterbolus thickness (at the antenna periphery) at each body area.

Fig. 10 shows the impedance matching of the antenna at the three body areas with the optimum waterbolus and air-gap combination. The curvature at the back of the head produced the least aperture loading by the tissue. The waterbolus thicknesses at the antenna periphery were 22 - $34 \mathrm{~mm}$ which takes account of possible volume and surface wave oscillations. 


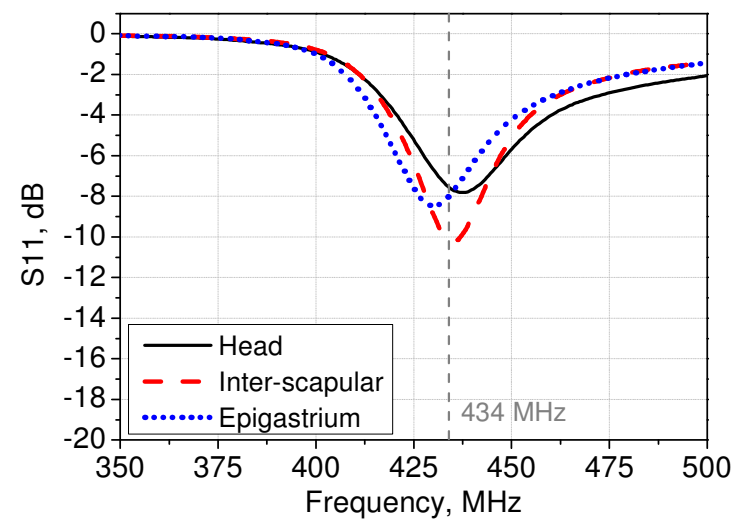

Figure $10\left|S_{11}\right|$ for the optimum waterbolus and air-gap combination for the heterogeneous body model

The higher peak SAR, which occurred at the head, correlates with an increased tangential E-field that typically aligns with the tissue layers. The deepest SAR penetration at the head, inter-scapular and epigastrium locations are located in grey matter, muscle and small intestine, respectively. These tissues have comparable conductivity-to-density ratios.

The SAR has been linked to the permittivity gradient between interfacing tissues [27]. The peak SAR at the targeted body areas in the heterogeneous model for the head, inter-scapular and epigastrium positions are $34.4 \%, 28.9 \%$ and $35.6 \%$ higher than the equivalent homogeneous body models. In general, the SAR penetration is deeper in the homogeneous muscle equivalent models than the heterogeneous tissues. The head position incurred the least power penetration due to the higher absorption rates of the superficial tissues.

The head region presents the highest peak SAR for both the homogeneous muscle and the heterogeneous body models. For the heterogeneous models, the peak SAR is reduced by $4.21 \%$ between the head and epigastrium region and by $17.6 \%$ between the head and inter-scapular region. For the homogeneous muscle model, the peak SAR is reduced by $5.95 \%$ between the head and epigastrium region and $10.7 \%$ between the head and inter-scapular region.

The required input power to get the $43{ }^{\circ} \mathrm{C}$ threshold is inversely proportional to the obtained peak SAR at the different body locations. Slight variations are due to the different thermal properties of the tissues at the different locations. The skin and muscle tissues has a perfusion rate that is $76 \%$ and $44 \%$ higher than fat, respectively. This will require a higher input power to achieve the target temperature of $43^{\circ} \mathrm{C}$ when tissue perfusion rates are increased for the inter-scapular region, as shown in Table $\mathrm{V}$.

TABLE V Input Power Required for $43{ }^{\circ} \mathrm{C}$ temperature Objective for the Heterogeneous Body Model

\begin{tabular}{lccc}
\hline \hline Body Position & SAR & Power for base & Power for doubled \\
& $(W / K g)$ & perfusion rates $(W)$ & perfusion rates $(W)$ \\
\hline Head & 6.41 & 75 & 79
\end{tabular}


Inter-scapular

Epigastrium
99

81

\section{Conclusions}

Single element near-field antenna applicators for superficial hyperthermia treatment require detailed anatomical modelling to take account of the thermal response and should inform on the design performance. A $434 \mathrm{MHz}$ compact patch designed for stable resonance in close proximity to different tissue types and shapes achieves good coupling performance at three areas on a full body model. The selected source power levels and the energy coupling overcome that natural tissue cooling due to vascular perfusion and perspiration to raise the local temperatures. Notwithstanding the complexity of the anatomy at the various treatment locations, the results indicate that the antenna design features produce a stable energy pattern to target tissue at the centre of the compact applicator geometry.

Contrasted with homogeneous and planar-layered models, the heterogeneous anatomical model reveals how the clinical treatment setup with surface-cooling waterboluses and the patient features influence the SAR patterns. The optimum waterbolus and air-gap dimensions were determined by balancing the impedance matching of the antenna and SAR outcomes. The antenna was modelled at the rear of the head, between the shoulder blades (inter-scapular) and in front of the stomach (epigastrium). The differing surface shapes, sub-dermal features and thermal responses necessitate that different input power levels are selected to achieve equivalent heating effects at the three experimental treatment areas. The input power required to achieve the target temperature of $43{ }^{\circ} \mathrm{C}$ was inversely proportional to the peak SAR. The analysis was limited by the static thermal parameters of the model. By doubling the perfusion rates in the tissues, the required input power increased from $75 \mathrm{~W}$ to $79 \mathrm{~W}$ for the head, $92 \mathrm{~W}$ to $99 \mathrm{~W}$ for the inter-scapular and $78 \mathrm{~W}$ to $81 \mathrm{~W}$ for the epigastrium positions. This quantifies the required power levels for clinical treatment scenarios.

\section{Acknowledgments}

The authors would like to thank TACONIC Advanced Dielectric Division for the antenna materials and Mr. V. Thorne,

Dr. H. Tinsley and Dr. J. Murphy for their biomedical guidance. This work was funded by the Irish Research Council for Science, Engineering and Technology's Embark Initiative Postgraduate Scholarship Scheme. It was also supported by Science Foundation Ireland through the CTVR Telecommunications Research Centre and by the Institute for Infocomm Research in Singapore. 


\section{$7 \quad$ References}

[1] Horsman M. R., Overgaard J., 'Hyperthermia: a potent enhancer of radiotherapy', Clinical Oncology, 2007, 19, (6), pp. $418-426$

[2] Ichinoseki-Sekine N., Naito H., Saga N., Ogura Y., Shiraishi M., Giombini A., Gionvannini V., Katamoto S., 'Changes in muscle temperature induced by $434 \mathrm{MHz}$ microwave hyperthermia', British Journal of Sports Medicine, 2007, 41, (7), pp. $425-429$

[3] Trujillo C.J., Leija, L., Vera, A., 'Design and Preliminary Evaluation of a superficial applicator for hyperthermia with a new coaxially fed antenna: Theoretical models', Pan American Health Care Exchange, Lima, Peru, March 2010, pp. 62-67

[4] Samaras T., Christ A., Klingenbock A., Kuster N., 'Worst case temperature rise in a one-dimensional tissue model exposed to radiofrequency radiation', IEEE Trans. Biomed. Eng., 2007, 54, (3), pp. 492-496

[5] Bahl I. J., Stuchly S. S., Lagendijk J. W., Stuchly M. A., 'Microstrip loop radiators for local hyperthermia', in Proc. IEEE MTT-S Int. Microw. Symp., Los Angeles, CA, USA, Jun 1981, pp. 465-467

[6] Curto S., Ammann M. J., 'Electromagnetic coupling mechanism in a layered human tissue as benchmark for $434 \mathrm{MHz}$ RF hyperthermia applicators', in Proc. IEEE Antennas Propagat. Society Int. Symp., Albuquerque, NM, USA, 2007, pp. 3185-3188

[7] Neuman D. G., Stauffer P. R., Jacobsen S., Rossetto F., 'SAR pattern perturbations from resonance effects in water bolus layers used with superficial microwave hyperthermia applicators', Int. J. Hyperthermia, 2002, 18, (3), pp. 180-193

[8] Gelvich E. A., Mazokhin V. N., 'Resonance effects in applicator water boluses and their influence on SAR distribution patterns', Int. J. Hyperthermia, 2000, 16, (2), pp. 113-128

[9] Lagendijk J. J. W., 'Hyperthermia treatment planning', Phys. Med. Biol., 2000, 45, (1), pp. 61-76

[10] Paulides M. M., Bakker J. F., Chavannes N., Van Rhoon G. C., 'A patch antenna design for application in a phased-array head and neck hyperthermia applicator', IEEE Trans. Biomed. Eng., 2007, 54, (11), pp. 2057-2063

[11] Curto S., McEvoy P., Bao X. L., Ammann M. J., 'Compact patch antenna for electromagnetic interaction with human tissue at 434 MHz', IEEE Trans. Antennas Propagat., 2009, 57, (9), pp. 2564-2571

[12] Mason P. A., Hurt W. D., Walters T. J., D'Andrea J. A., Gajsek P., Ryan K. L., Nelson D. A., Smith K. I., Ziriax J. M., 'Effects of frequency, permittivity, and voxel size on predicted, specific absorption rate values in biological tissue during electromagnetic-field exposure', IEEE Trans. Microw. Theory Tech., 2000, 48, (11), pp. 2050-2058

[13] Tinniswood A. D., Furse C. M., Gandhi O. P., 'Power deposition in the head and neck of an anatomically-based human body model for plane wave exposures', Phys. Med. Biol., 1998, 43, (8), pp. 2361-2378 
[14] Li Z., Maccarini P. F., Arabe O. A., Stakhursky V., Joines W. T., Stauffer P. R., 'Towards the validation of a commercial hyperthermia treatment planning system', Microwave Journal, 2008, 51, (12), pp. 28-42

[15] Ackerman M. J., 'The visible human project', Proc. IEEE, 1998, 86, (3), pp. 504-511

[16] http://www.remcom.com/ REMCOM - Electromagnetic Simulation Software, accessed December 2010

[17] http://niremf.ifac.cnr.it/tissprop/ IFAC CNR - Institute for Applied Physics. Italian national research council, accessed December 2010

[18] IEEE Std. 1528-2003, 'IEEE Recommended practice for determining the peak spatial-average specific absorption rate (SAR) in the human head from wireless communications devices: measurement techniques', 2003.

[19] Paulides M. M., Bakker J. F., Neufeld E., Van der Zee J., Jansen P. P., Levendag P. C., Van Rhoon G. C., 'The HYPERcollar: A novel applicator for hyperthermia in the head and neck', Int. J. Hyperthermia, 2007, 23, (7), pp. $567-576$

[20] Lee H. K., Antell A. G., Perez C. A., Straube W. L., Ramachandran G., Myerson R. J., Emami B., Molmenti E. P., Buckner A., Lockett M. A., 'Superficial hyperthermia and irradiation for recurrent breast carcinoma of the chest wall: prognostic factors in 196 tumors', Int. J. Rad. Onc. Biol. Phys., 1998, 40, (2), pp. 365-375

[21] Van der Zee J., Vujaskovic Z., Kondo M., Sugahara T., 'The Kadota fund international forum 2004-Clinical group consensus', Int. J. Hyperthermia, 2008, 24, (2), pp. 111-122

[22] Sapareto S. A., Dewey W. C., 'Thermal dose determination in cancer therapy', Int J Radiat Oncol Biol Phys., 1984, 10, (6), pp. 787-800

[23] Dewhirst M. W., Vujaskovic Z., Jones E., Thrall D., 'Re-setting the biologic rationale for thermal therapy', Int. J. Hyperthermia, 2005, 21, (8), pp. 779-790

[24] Pennes H. H., 'Analysis of tissue and arterial blood temperatures in resting human forearm', J. Appl. Physiol. 1948, 1, (2), pp. $93-122$

[25] Schmid and Partner Engineering AG, 'DASY4 Dosimetric Assessment System Manual' (1 $1^{\text {st }}$ edn. 2002)

[26] Bruijne M., Samaras T., Chavannes N., Rhoon G.C., 'Quantitative validation of the 3D SAR profile of hyperthermia applicators using the gamma method', Phys. Med. Biol., 2007, 52, (11), pp. 3075-3088

[27] Gajsek P., Hurt W. D., Ziriax J. M., Mason P. A., 'Parametric dependence of SAR on permittivity values in a man model', IEEE Trans. Biomed. Eng., 2001, 48, (10), pp. 1169-1177

\section{Appendix}

This section contains Table I and Table II with the conductivity, density, relative permittivity and thermal properties values for the simulated body tissues.

TABLE I Tissue Dielectric Properties of Simulated Areas in Human Body Model at $434 \mathrm{MHz}$ 


\begin{tabular}{|c|c|c|c|c|}
\hline Material & "Relative Permittivity, $\varepsilon_{r}$ & "Conductivity, $\sigma(\mathrm{S} / \mathrm{m})$ & Density, $\rho\left(\mathrm{kg} / \mathrm{m}^{3}\right)$ & $\begin{array}{l}\sigma / \rho \text { ratic } \\
\times 10^{-4}\end{array}$ \\
\hline Blood & 63.826 & 1.361 & 1058 & 12.9 \\
\hline Cancellous bone & 22.257 & 0.241 & 1920 & 1.26 \\
\hline Cartilage & 45.140 & 0.598 & 1097 & 5.45 \\
\hline Cortical bone & 13.071 & 0.094 & 1990 & 0.47 \\
\hline Cerebrospinal fluid & 70.630 & 2.260 & 1007.2 & 22.40 \\
\hline Grey matter & 56.814 & 0.751 & 1038 & 7.24 \\
\hline Lung & 23.579 & 0.380 & 260 & 14.6 \\
\hline Muscle & 56.866 & 0.805 & 1046.9 & 7.69 \\
\hline Nerve & 35.038 & 0.455 & 1038 & 4.39 \\
\hline Pancreas & 47.120 & 0.568 & 1220 & 4.66 \\
\hline Skin & 46.059 & 0.702 & 1125 & 6.24 \\
\hline Small intestine & 65.266 & 1.922 & 1042.5 & 18.4 \\
\hline Stomach & 67.186 & 1.013 & 1050 & 9.65 \\
\hline White matter & 41.659 & 0.451 & 1038 & 4.35 \\
\hline Yellow marrow, fat & 5.566 & 0.041 & 916 & 0.45 \\
\hline
\end{tabular}

TABLE II Tissue Thermal Properties of Simulated Areas in Human Body Model at $434 \mathrm{MHz}$

\begin{tabular}{|c|c|c|c|c|}
\hline Material & $\begin{array}{l}\text { Heat Capacity, } \\
\qquad C\left(\mathrm{~J} / \mathrm{kg} /{ }^{\circ} \mathrm{C}\right)\end{array}$ & $\begin{array}{l}\text { Thermal Conductivity, } \\
\qquad K(\mathrm{~W} / \mathrm{m} / \mathrm{C})\end{array}$ & $\begin{array}{l}\text { Perfusion, } \omega \\
(\mathrm{ml} / 100 \mathrm{~g} / \mathrm{min})\end{array}$ & $\begin{array}{c}\text { Metabolic heat, } Q_{m} \\
\left(\mathrm{~W} / \mathrm{m}^{3}\right)\end{array}$ \\
\hline Blood & 3600 & 0.51 & 1000 & 0 \\
\hline Cancellous bone & 2238 & 0.36 & 3 & 0 \\
\hline Cartilage & 3400 & 0.45 & 14.3 & 1000 \\
\hline Cortical bone & 1300 & 0.36 & 1.4 & 0 \\
\hline Cerebrospinal fluid & 4200 & 0.60 & 0 & 0 \\
\hline Grey matter & 3680 & 0.56 & 67.1 & 5370 \\
\hline Lung & 2354 & 0.45 & 40 & 0 \\
\hline Muscle & 3500 & 0.49 & 5 & 758 \\
\hline
\end{tabular}


Nerve

Pancreas

Skin

Small intestine

Stomach

White matter

Yellow marrow, fat
3640

3600

3150

3600

3500

3600

2300
0.53

0.51

0.34

0.55

0.52

0.50

0.23
56

100

12

100

40

23.7

2.8
332.1

390.4

1125

333.6

703.5

5370

293.1 